\title{
Structured relations between higher education institutions and external organisations: opportunity or bureaucratisation?
}

\author{
Anders Broström $^{1}$ (D) $\cdot$ Andreas Feldmann ${ }^{1} \cdot$ Matti Kaulio $^{1}$ \\ Published online: 31 January 2019 \\ (C) The Author(s) 2019
}

\begin{abstract}
This paper explores the introduction of centrally coordinated initiatives aimed at formalising universities' relationships to external organisations. Such initiatives are referred to as structured relations. Based on a review of nine Swedish Universities, we identify three types of structured relation initiatives (network events, collaboration platforms, partnership agreements). In common for all structured relations identified are that they offer new opportunities to manage external expectations on universities, in particular as regards their ability to demonstrate their commitment to outreach activities. The formalisation of outreach activities challenges the academic tradition of giving individual professors discretionary mandates to enter and manage external relationships. Drawing on a collective action perspective, we analyse the tensions that are generated when universities introduce new elements of support and central coordination of outreach activities. The introduction of structured relations potentially contributes to changing the nature of the university as an organisation.
\end{abstract}

Keywords Entrepreneurial university · University-industry · Managerialism • Outreach · Technology transfer Academic engagement

\section{Introduction}

External engagement has increasingly moved into focus of university managers across the globe (Benneworth et al. 2016; Guerrero and Urbano 2012; Jongbloed et al. 2008). With government budgets for research and education under pressure in many countries, the everpresent need to secure funding beyond base grants for research and education moves up the ladder of priority (Maassen and Stensaker 2011; Pinheiro and Stensaker 2014a). In this context, relationships with external partners become increasingly important (Alarcón-delAmo et al. 2016; Heitor 2015). Strong relationships with external non-academic organisations

Anders Broström

anders.brostrom@indek.kth.se

1 Department of Industrial Economics and Management, KTH Royal Institute of Technology,

Stockholm, Sweden 
may help the university to, e.g. develop capabilities for fund-raising, attracting more ambitious engagement from individual firms and in establishing partnerships which enables the university to access funding from sources such as the EU's Horizon 2020 where collaboration with external organisations is an important requirement (Jones-Evans et al. 1999). Furthermore, there are discussions in many countries about reforms to introduce elements of 'relevance' and 'impact' into the allocation of research funding with the UK research excellence framework with its use of case studies to capture impact of research as a leading model (Geuna and Piolatto 2016).

Traditionally, universities have relied on a bottom-up approach when it comes to external engagement. Each researcher or research group has set up their own networks of contacts and channels for collaboration. University administrators and leaders can introduce procedures, guidelines and frameworks for interaction. In countries which have abolished the so-called professor's privilege, the use of immaterial rights produced in universities is also controlled by central administrative university functions. Beyond that, administrators' influence over the behaviour of individual academics is strongly dependent on commitment and leadership on behalf of respected academics. It is, therefore, difficult to commit the university as an organisation to agreements involving concrete activities which have to be performed by faculty with specialist competence. Such limitations effectively reduce the scope of what possible agreements between universities and external organisations that can be implemented.

In a situation where institutional legitimacy and funding become more strongly associated with external relationships, this practice constitutes an institutional risk. Firstly, there is a risk of too little engagement. Expectations on industry engagement are generally not specified in the employee contracts for researchers - at least not in a manner that allows for performance reviews - so it is up to each researcher to decide on how much they want to work with external partners. Secondly, the existing networks are person-dependent, meaning that if a key person leaves for another employment, there is a risk of losing sets of existing networks to external organisations entirely.

In this paper, we document and discuss how university management has begun to respond to such concerns by establishing a new kind of relationships between the university as an organisation and the outside world. Existing structures are typically aimed at facilitating research commercialisation (e.g. incubators, science parks and technology licencing offices; Klofsten and Jones-Evans 2000) or at providing institutionalised forms of university-industry relationships of more limited scope, e.g. special organisational arrangements such as centres and institutes with some form of joint governance between academics and industrial partners (Ponomariov and Boardman 2010).

Complementing such structures, the centrally coordinated initiatives studied here represent university-driven ambitions to stimulate exchange in teaching and research between academia and external organisations. Such exchange may, for example, take the form of increased industrial engagement in joint research with the university, increased inter-organisational mobility and industrially sponsored $\mathrm{PhD}$ education.

We refer to university-wide initiatives seeking to strengthen these types of exchange as establishing structured relations. More precisely, we define structured relations as initiatives to strengthen a university's formalised interaction with non-academic organisations with the following properties: (1) decided on by (but not necessarily originally conceived by) central leadership; (2) centred on faculty involvement; (3) supported by university employees in dedicated functions; (4) aiming at bi-directional exchange (beyond the scope of a specific call). 
With universities establishing centrally organised activities and forms of interactions with non-academic organisations and stakeholders, new opportunities-but also new tensions - arise. In the following section, we explore the inherent tensions between the introduction of centrally conceived procedures for interaction and the traditionally decentralised nature of relationships in the university organisation. The 'Methodology' and 'Findings' sections present methodology and findings from a review of structured relation initiatives at nine Swedish universities. 'Conclusion', finally, summarises the discussion and elaborates directions for further empirical and theoretical exploration of the opportunities and challenges connected to university initiatives to institutionalise and formalise relationships with external organisations.

\section{Individual agency and the institutionalisation of outreach}

\section{A legacy of individual action}

We consider the organisation of universities from a collective action perspective (Olson 1971). Our point of departure is a view of universities as being embedded in scholarly culture of professional autonomy. The notion of academic freedom is typically evoked to establish a limitation on political and interest group influence over the teaching and research activities of academics (Altbach 2001), but is also interpreted more broadly as a right to autonomous behaviour by faculty. In consequence, top-down decision-making plays a less accentuated role in universities than in many other types of organisations (Cohen et al. 1972; Blaschke et al. 2014). Not only is subject expertise seen as the most legitimate basis for many decisions, such expertise is also fragmented across the various disciplines and scientific areas of expertise represented in the organisation. The loyalty of many individuals is primarily oriented towards their field, disciplines and scientific peers (Becher and Trowler 2001). Representatives of the university in which they happen to be currently employed cannot always count on the same type of loyalty towards the organisation.

As a result of these characteristics, universities are often described as 'bottom-heavy' organisations which generally have low potency for collective action (Clark 1983; Gornitzka 1999; Olsen 2007). Studies on the role of strategies in universities have, as a consequence, tended to describe these as 'a ceremonial act of compliance with environmental demands' (Fumasoli and Lepori 2011), as mostly adaptive (Maassen and Potman 1990) or as one of several inputs into complex and non-transparent decision processes (Weick 1976). However, it has also been repeatedly contended that universities are-in response to external pressure to act 'strategically' - moving towards greater centralisation, and that thereby academic freedom or autonomy at the sub-unit, group and individual levels may be seriously threatened (Tapper and Palfreyman 2011; Trow 1994). A possible reconciliation of these two views, it may be argued that contemporary universities maintain both elements of the organisational archetype 'organised anarchy', which has been used extensively in organisational studies of academia (Cohen et al. 1972), and elements of strategic actorhood (e.g. Krücken and Meier 2006).

As university-wide initiatives seeking to strengthen a university's formalised interaction with non-academic organisations, the introduction of structured relations may be understood as a shift towards collective action. Against the view of competing, co-existing logics of individual and collective action outlined above, we ground our analysis of such initiatives in a delineation 
of rationales for collective action. Specifically, we are in this study concerned with the problem of mobilising academics for collective action regarding contacts with external, non-university, organisations. The rationale for collective action in this domain of activity can be understood in relations to inherent limitations of individual action. We therefore next turn to the following question: What are the characteristics of external relationships which may require collective action?

\section{Structured relations and the potential of collective action}

Following previous research on inter-organisational exchange in the tradition of the sociology of organisations, we identify three key dimensions of an organisation's external relationships (c.f. Koput 1997; Laursen and Salter 2006). The first of these is the number of relationships in which an organisation is involved, i.e. the breadth of relationships. The second two dimensions are characteristics of the depth of a specific relationship. We draw on Lefton and Rosengren (1966) and Kaulio (1998) in classifying relationships by their temporal duration and thematic scope.

Table 1 lists limitations of individual action, and the associated opportunities to overcome these limitations, along these three dimensions.

Our characterisation of external relationships along the three dimensions of Table 1 provides us with an analytical framework on which we may base our empirical investigation of the phenomenon structured relations. Specifically, it offers an analytical scheme against which a specific structured relation initiative may be mapped, in terms of what limitations of individual action that the initiative seeks to address.

\section{Structural relations and barriers to collective action}

Initiative to structure external relationship is a considerable departure from the tradition of 'ad hoc' relationships between faculty and external partners, and of professorial self-governance in

Table 1 Inherent limitations of individual action in external relationships

\begin{tabular}{|c|c|c|}
\hline Dimension & Limitation of individual action & Potential for collective action \\
\hline Number of relationships & $\begin{array}{l}\text { An individual academic is limited in his } \\
\text { or her ability to engage in } \\
\text { relationship-building } \\
\text { efforts with multiple actors by the ef- } \\
\text { fort } \\
\text { required. }\end{array}$ & $\begin{array}{l}\text { Division of labour, where } \\
\text { relationship-building actions } \\
\text { are partly transferred to specialist } \\
\text { functions }\end{array}$ \\
\hline $\begin{array}{l}\text { Duration of a specific } \\
\text { relationship }\end{array}$ & $\begin{array}{l}\text { A relationship is disrupted when the } \\
\text { individual academic leaves his or her } \\
\text { position, when the relationship no } \\
\text { longer satisfies the personal interest of } \\
\text { the academic, or when efforts needed } \\
\text { to maintain the relationship are } \\
\text { crowded out by other duties and } \\
\text { activities. }\end{array}$ & $\begin{array}{l}\text { Avoiding disruption of valuable } \\
\text { relationships due to personnel } \\
\text { mobility by formalising and } \\
\text { institutionalising relationships }\end{array}$ \\
\hline $\begin{array}{l}\text { Scope of a specific } \\
\text { relationship }\end{array}$ & $\begin{array}{l}\text { A specific relationship is bounded in } \\
\text { terms of content by the interest of the } \\
\text { individual academic. }\end{array}$ & $\begin{array}{l}\text { Offering a broader interface of interaction } \\
\text { towards an external stakeholder by } \\
\text { coordinating university expertise }\end{array}$ \\
\hline
\end{tabular}


a mode of individual action. It follows naturally from our description of structured relations as leveraging potential for collective action to consider resistance towards such initiatives.

Collective action theory suggests that we may understand the preference of university professors to retain full control over external relationships as a social dilemma (Ostrom 1998), where individuals with agency hesitate to contribute to the generation of public goods.

In transforming external relationship management from being exclusively an activity for individual academics to being partly subjected to organisational control, public good characteristics are introduced. In traditional professor-centred relationships, the individual academic is both taking on the effort to build and maintain relationship and enjoying much of its benefits (e.g. the mobilisation of resources for activities performed by, or sanctioned by, the individual academic). The institutionalisation of external relationships, however, introduces a partial separation between relationship-building efforts and the benefits of resource mobilisation from external relationships. This introduces potential free-riding problems and, hence, reluctance among individuals towards collective action. Unless carefully aligned with existing ambitions and motivations of individual academics, any structures imposed on interaction with external organisations will therefore tend to be ignored, if not actively opposed.

Hence, it may be argued that the implementation of structured relation initiatives requires a delicate act of balance. On the one hand, an initiative must allow the organisation to take significant steps beyond what can be achieved through uncoordinated individual action. Looking back at Table 1, this means that the initiative allows for a broader spectrum of relationships, for relationships of considerable longer duration, for relationships of considerable broader thematic scope, or a combination of these. On the other hand, the more ambitious the initiative in terms of demands for academics to adapt to organisational procedure and in terms of support from specialised functions, the greater the tensions (and hence resistance) surrounding the initiative. Collective action theory suggests that the success of organisational reforms introducing elements of collective action requires successfully making visible public good benefits to build acceptance (Olson 1971).

\section{Methodology}

This research set out to investigate the phenomenon structured relations through a review of existing initiatives in this area among Swedish higher education institutions (HEIs). All larger domestic HEIs were contacted to participate in the project. Since the project required in-kind financing from the participating universities, as well as upper management participation, their commitment was secured. In the end, nine universities joined the study (see Table 2). Together, these nine HEIs are representative of Swedish academia at large. Among them, we find five comprehensive universities, two single-faculty (specialised) universities as well as two HEIs with the formal status of University College in the Swedish HEI-system.

At each university, the senior representative responsible for developing university strategy regarding external engagement (typically the prorector or a vice rector) was involved and engaged in both providing the upper management perspective at each university and selecting initiatives for further study, thus ensuring the strategic importance of the initiatives under study.

The research was divided into two phases. The first phase was characterised by exploration, where the phenomenon structured relations was investigated. At the beginning of this phase, the authors did not have a name for the phenomenon. The aim of the first phase was to identify avenues for further exploration with respect to structured relations. The data collection in the 
Table 2 Sample universities

\begin{tabular}{llr}
\hline HEI & Type & Turnover (in MSEK) \\
\hline Jönköping University & University college & 931 \\
Linköping University & Comprehensive & 3734 \\
Lund University & Comprehensive & 8113 \\
Mälardalen University & University college & 914 \\
Swedish University of Agricultural Sciences & Specialised & 3350 \\
Royal Institute of Technology & Specialised & 4426 \\
Stockholm University & Comprehensive & 4930 \\
Umeå University & Comprehensive & 4221 \\
Uppsala University & Comprehensive & 6643 \\
\hline
\end{tabular}

first phase was carried out by one of the authors (Broström), through semi-structured interviews with the senior university manager responsible for developing external engagement at each of the nine participating HEIs. Each interview lasted approximately one hour and covered strategic priorities with regard to external engagement and organisation of engagement activities as well as evaluation systems for external engagement. As complement to the interviews, a workshop with all interviewees was arranged to synthesise and validate the findings from the interviews.

As a result of work in the first phase, a definition of structured relations was developed along with the analytical framework presented in the 'Structured relations and the potential of collective action' section. Furthermore, it was found from a first review of structured relation initiatives that it was analytically meaningful to group initiatives into three clusters, according to the three dimensions of our analytical framework (the number of external actors involved, duration and thematic scope; see Table 1). Table 3 offers on overview of the three resulting types of structured relations, named network events, platforms and partnerships.

During the second phase of the research, which took place throughout most of the year 2014, the identified types of structured relations were populated with examples and studied more in depth. The data collection in this phase was conducted in a distributed arrangement. Three teams of administrative employees from the participating HEIs were screening the participating universities for structured relation initiatives. Each team was led by a senior representative for university leadership (vice rector, prorector). The data collection process was coordinated across institutions through a series of meetings and workshops, with one of the authors

Table 3 A classification of structured relation initiatives

\begin{tabular}{|c|c|c|c|c|}
\hline $\begin{array}{l}\text { Type of } \\
\text { structure }\end{array}$ & $\begin{array}{l}\text { Number of } \\
\text { external } \\
\text { organisations } \\
\text { involved }\end{array}$ & Duration & Thematic scope & $\begin{array}{l}\text { Number of } \\
\text { initiatives } \\
\text { studied }\end{array}$ \\
\hline $\begin{array}{r}\text { Network } \\
\text { events }\end{array}$ & $10+$ & One day + follow-up & $\begin{array}{l}\text { Thematically oriented, often with } \\
\text { highly specialised sessions }\end{array}$ & 8 \\
\hline $\begin{array}{l}\text { Collaboration } \\
\text { platforms }\end{array}$ & $3-15$ & $\begin{array}{l}\text { Subject to continuous } \\
\text { evaluation and mutual } \\
\text { decisions about } \\
\text { continuation }\end{array}$ & Thematically oriented & 9 \\
\hline $\begin{array}{l}\text { Partnership } \\
\text { agreements }\end{array}$ & 1 & $\begin{array}{l}\text { Set up over a fixed, } \\
\text { multi-year time period, } \\
\text { with expectations on re- } \\
\text { newal }\end{array}$ & $\begin{array}{l}\text { Broad; encompassing all issues of } \\
\text { mutual interest to the university } \\
\text { and the partner organisation }\end{array}$ & 9 \\
\hline
\end{tabular}


(Feldmann) taking the role as coordinator. A general research protocol was drafted for all participants and specific interview guides and survey questions from the local teams were reviewed and shared with the whole project group.

In total, 56 different initiatives were identified. These were described in terms of the three dimensions of Table 1, and mapped onto the three categories of Table 3. Twenty-five initiatives were selected for in-depth studies. Selection was based on analytical sampling (c.f. Yin 1989), in that cases were selected to cover as many different types of initiatives as possible. The initiatives that were not included in the study were considered duplicates of already included initiatives and structures.

Key focus for the in-depth analysis was to study resource dedication and incentives, both to build the structure and to populate the structure. Furthermore, narratives and logics regarding the underlying purpose of the structure were documented. In particular, data was collected on the background to the introduction on each initiative in terms of key actors and events. Beyond the scope of this study, each local team also worked to answer additional research questions, specific to their context and type of initiative.

At the local level, data for the second phase of the study was collected through a mixed interview and document study, drawing on public disclosures as well as internal documents. These combinations allowed for data triangulation. The interviews were semi-structured and followed a joint research protocol in the aspects relevant for this study. Depending on the nature of the studied initiatives, some initiatives were also studied using questionnaires in addition to interviews and documents.

An advantage with a distributed research process such as conducted here is that it combines in-depth understanding of each HEI and expertise from the local team with objectivity and theoretical understanding of the academic project leaders. An obvious downside is that the approach limits researchers' access to first-hand contact with the 'raw' empirical data. Rather parallel to work carried out through the construction of a survey or collection of other types of quantitative data, a distributed approach such as ours limits researchers' exposure to unexpected findings and insights. Conducting appropriate pre-survey testing and investigation (as in the first phase of this research effort) helps mitigate concerns about neglecting important dimensions or aspects. Furthermore, researchers need to make sure that they can ensure the validity of data collected by others. Continuous discussions with both the local teams and the responsible university leaders throughout the review process did in this case offer significant opportunity to double-check findings and probe further into unresolved or unclear issues regarding the studied initiatives. To further complement the data and to allow for better cross case analysis, interviews with the data collectors were carried out (Torbert and Taylor 2008). Finally, the authors have conducted a final round of interviews with the director of external engagement at each of the nine participating HEIs. These were performed at the end of the project to verify the findings.

\section{Findings}

A first finding from our study is that the structured relation initiatives which were identified could be clustered into three groups. As described in the previous section, groups were identified on the basis of our analytical framework of Table 1 . That is, groups differ in the number of external actors involved, the duration of relationships and the thematic scope of a relationship. Each group thus represents an ambition to overcome a specific set of limitations of individual action. 
Within each of these clusters, 8-9 initiatives were selected for in-depth study. Table 3 offers an overview of these three types of structured relations.

Throughout the in-depth analysis of 25 initiatives, opportunities and tensions of collective action through structured relations have been reviewed. In order to place the general development of structured relations in perspective, we have also analysed the emergence of these initiatives.

\section{Network events}

The first cluster of initiatives can be described as network events, i.e. events organised to facilitate meetings with potential collaborators. The relationship managed in these structures is short in duration and typically limited in thematic scope (at least in the initial 'structured' phase), but they address a large number of external organisations.

In recent years, several of the universities that were reviewed had begun organising events to meet and establish contacts with potential external industry collaborators. These are organised by staff in dedicated liaison support office of the type normally involved also in partnership agreements and collaboration platforms. The university's commitment here is restricted to matching interested firms with appropriate faculty contacts, and setting up meetings to take place during a dedicated day in 'fair-like' environment. Any further collaboration must be negotiated from there; there is no commitment from either side to do more than meet and talk.

The quintessential example - and the model for many other initiatives of this kind - is the AIMday format that has been developed by Uppsala University and spread to several other HEIs. AIMdays are arranged around varying thematic areas, during 2014, e.g. 'bioimaging', 'big data', 'materials', 'cancer', 'ICT', 'modelling \& simulation', 'and disabilities'. Irrespective of the theme, however, the format remains the same. In the first step, organisations interested in interacting with the university are invited to submit questions that they want to discuss. Under guidance from liaison office personnel, faculty then 'sign up' for questions that they, based on their interests and expertise, want to discuss. A schedule for a full day of group discussions is then set up. Each question is assigned a one-hour slot in groups of 7-12 people, while making sure for the schedule to contain ample space for mingling and follow-up discussions. The last activity to which the university is committed takes place about one month after the AIMday event, when the liaison officers follow up on the meetings. Through this contact, or through further interaction between firm and faculty, a promising relationship may be transferred to other structured relation initiatives at the university (i.e. collaboration platforms).

The [AIMday] event gives an opportunity for organisations from industry and the public sector to meet university researchers, discuss their challenges, establish contacts and exchange knowledge. Industry liaison officer

Network events allow the university to overcome inherent limitations of individual action in networking, by means of creating an interface for inter-organisational exchange. To function, two types of collective action must be introduced: an indirect form whereby resources are shifted to centrally run support services and a direct form whereby academics comply with thematic priorities and organisational arrangements outside their direct control.

\section{Collaboration platforms}

The second cluster is collaboration structures which we here refer to as collaboration platforms. These initiatives involve an intermediate number of external actors. Similar to network events, 
initiatives in this category of structured relations are relatively well-defined in terms of thematic scope. Whereas meeting events have a short duration, however, interaction structured as collaboration platforms takes place over a significant time span. Successful platforms may remain active for years. These structures, which typically involve several different academics, may survive over fairly long times, sometimes evolving into broader relationships. In their original form, however, commitments for collaboration are often made on a shorter timehorizon (intermediate duration).

Among the examples of collaboration platforms that were identified in the review, it was not unusual for third-party funding (e.g. from a regional body or a national authority) to play a role. Such funding was typically made available in order to stimulate university-industry interaction.

The review on which this study is based engaged with nine cases of collaboration platforms, selected from among more than 20 candidates. These cases include the regionally oriented collaboration platform in the area of quality management and leadership within the health care sector set up by Jönköping University together with the local municipalities and the regional health care council. The collaboration platform is active since 2009 and its purpose is to both develop new knowledge on improved health care systems and to systematically make new developments available for practitioners in health care. The platform is funded through monetary engagement from the members as well as in-kind contributions. The platform supports projects such as the regional colon cancer project, which sets out to develop a formal process for colon cancer patients. Another project sets out to capture the patients as resources, both for innovation and for improvements. While the projects are explicitly time-limited, the platform itself is not.

In the context of our analytical framework, as developed in Table 1, collaboration platforms constitute a solution to limitations of individual action similar to those addressed by the introduction of network events. This form of temporal organisation provides the university with an opportunity to offer a broader interface for interaction over longer periods of time, and with reduced risks of disruption due to individual-level factors.

\section{Partnership agreements}

A third cluster of structured relation initiatives is partnership agreements. Three of the universities participating in the review had entered into 15 different one-to-one agreements with a partner organisation. The partners were industrial firms and bodies of regional administration (counties, municipalities), which had been identified as stakeholders with a significant level of present (direct or indirect) relationships to the respective university.

These types of initiatives are characterised by being expected to cover considerable scope, i.e. to involve academics from different parts of the university for different problems of interest to the partner organisation, and to be expected to be in place for a relatively long time. They also tended to involve both teaching (i.e. student-centred) and research-related (i.e. centred on $\mathrm{PhD}$ students and faculty) exchange.

A joint property of the partnership agreements was that they stipulated forms for high-level interaction between the university and the partner, including forms for mutual evaluation of the partnership. They also stipulated what resources that the partners were committing within a specified time period (ranging from one to four years).

It is notable that university commitments in these partnerships typically were rather limited (or vague) in terms of direct funding, and in terms of faculty participation. The objective of the partnership agreements focused on securing the continuous attention of senior managers from 
both sides (including the participation of the rector in annual partnership reviews and meetings) and on establishing an administrative support structure for future contacts. As such, it is clear that universities are seeking to overcome some particular limitations associated with individual action in the domain of external relations, but also that they remain cautious about the conflicting interest of preserving academic autonomy and exploiting opportunities of collective action.

An example of a partnership agreement is that between KTH Royal Institute of Technology and Ericsson, an ICT multinational founded and based in Sweden. With corporate and R\&D headquarters in Stockholm, recruitment from and collaboration with KTH have long been of importance to Ericsson. When existing ad hoc and individual-level relationships were complemented with a formal partnership agreement in 2012, the focus was set on establishing new dialogue about aligning the university's educational offerings to changing industrial realities, and to promote international student recruitment. The partners also, however, sought dialogue on new potential collaborations in research.

Many actors at KTH confirm that the strategic partnerships have led to improved dialogue with industry. In particular, communication with top management has been strongly facilitated. Excerpt from the KTH Administrative Assessment Exercise 2014 Report

Notably, Ericsson did during 2014 enter into a separate agreement with KTH, providing funding for a 17 million Euro joint venture research centre in the transport area.

\section{The emergence of structured relation initiatives}

We would argue that these initiatives to a significant extent have emerged in contexts characterised by direct and indirect interventions by external policy actors. First, we find that several of the initiatives that were identified in our review (in particular those that we refer to as 'collaboration platforms' above) were supported and co-funded by national or regional policy bodies with an interest in promoting university-industry relationships (c.f. Benneworth and Jongbloed 2010). Secondly, the introduction of structured relation initiatives can be understood as a managerial response to increased demands from the national government to demonstrate clear strategies for - and results from — outreach and collaboration (Redford and Fayolle 2014). Structured relation initiatives provide central university representatives with actions and structures to showcase as evidence of their commitment towards encouraging external relationships. It is therefore logical that we find that the establishment of structured relations seems strongly linked to the presence of internal champions with considerable legitimacy (Bstieler et al. 2015). Furthermore, it is noteworthy that structured relation initiatives in some instances are championed by existing industry liaison offices seeking to legitimise their activities and to gain a more clearly defined role within the university.

The spreading of structured relations across our nine reviewed universities would furthermore seem to contain important elements of institutional isomorphism (DiMaggio and Powell 1983). For example, the AIMday format for events as well as the principles for establishing partnership agreements had already at the time of our review started to diffuse between universities (Jonsson et al. 2015). A key motivation for universities to participate in the review that was reported in this study was to facilitate further sharing of experiences from existing structured relation initiatives. Beyond such mimetic isomorphism, we note signs of coercive 
isomorphic change in that external partners tend to bring with them experiences and expectations regarding the forms of interaction between their different university contacts.

\section{Tensions}

The structured relation initiatives that we have identified here have been introduced as complements to traditional forms of 'grass roots' engagements, not as a replacement. At all of the nine universities that took part in the review, the introduction of new initiatives had not changed the formal delegation of authority to individual academics to work with industry or other stakeholders in the way they saw fit. Furthermore, we observe that resource flows built into the structured relations identified in the review often are set up so that direct funding derived from external partnership activities is channelled towards environments where the involved academics are active, rather than to 'strategic development' or brand new initiatives at the discretion of central decision-makers.

These observations imply that academic engagement is allowed to maintain much of its traditional logic of individual action. Proponents of structured relations, such as many of the university leaders and support staff participating in the review from which this paper draws its empirical material, are generally highly aware that moving strongly in a direction of collective rather than individual action would generate significant resistance within universities, and likely also be practically difficult to implement.

We have to move forward carefully, avoiding to step on toes where possible. While there is considerable support for our current strategy [of implementing structured relations] in the university leadership, we are also aware of critical voices among faculty. External relations support officer

While the introduction of stronger elements of collective actions that we observe thus is gradual and limited rather than radical, the implications for life at the university are not trivial. The introduction of structured relations contributes to a shift of authority within universities towards centrally placed decision-makers, in a development which is clearly mirroring a more general tendency towards ambitions for the university to 'act strategically' (Pinheiro et al. 2014). This authority is not exercised as direct control over the activities and relationships of individual faculty members, but rather as 'soft' power in the form of influence over who gets to be involved in forming structured relations. Individual faculty may find (or fear) that their ability to maintain and develop personally oriented relations to external stakeholders outside the scope of the structured relation interface decreases with the establishment of structured relations, as managerial attention and resources of a university's external partners are channelled through structured relations. In our study, we saw clear indications that the introduction of structured relationships was perceived as strengthening the pressure on individual faculty to engage with centrally placed offices, in order to coordinate their outreach activities and in order to not miss out on opportunities for future external collaborations. ${ }^{1}$ Thereby, the introduction of structured relations can be made formally compliant with academic autonomy, while still enabling collective action.

\footnotetext{
${ }^{1}$ Notably, the professor's privilege legislation that is in place in Sweden still places all rights to IPR in the hands of the individual faculty member. It can be posited that in countries where the university has a direct stake in IPR ownership, the introduction of structured relation initiatives may threaten individual autonomy in an even higher degree (c.f. Kenney and Patton 2009).
} 
When a steering group for the partnership [with firm X] was formed, those who like me already had well-developed contacts with [firm X] could not afford to stay out of that group since important decisions were being taken there. Professor

Consistent with our theoretical expectations, we see signs of tensions and resistance most notably surrounding initiatives which most clearly deviate from the practice of professorcentred relationships. For example, many of the initiatives which we have classified as collaboration platforms would seem to maintain many elements associated with traditional individual action, while also helping universities to present interfaces of interaction thematically broad enough to meet expectations from certain external stakeholders. Regarding partnership agreements, on the other hand, there are signs that the introduction of structured relations may strengthen existing tensions between different organisational levels of the university. $^{2}$

\section{Conclusion}

A consensus exists that universities are moving towards an organisational stance of strategic actorhood (Pinheiro and Stensaker 2014a). Plentiful observations from several countries suggest that over time, universities in many countries have adopted features of formalised, rationalised decision-making and strategic action lead by more powerful managers (Ramirez and Christensen 2012). They have thereby become more 'organisation-like' than before (Brunsson and Sahlin-Andersson 2000), while to a significant degree maintaining a strong element of bottom-up decision-making (Krücken et al. 2013; Musselin 2013). For example, centralisation of research commercialisation activities has been forcefully imposed on universities in many countries through national reforms, with the 1980 Bayh-Dole Act of the USA as the flagship example (Mowery et al. 2015).

In this paper, we argue that a parallel development is taking place regarding the wider spectrum of outreach activities commonly referred to as 'academic engagement' (e.g. joint research with industry, c.f. Boardman and Ponomariov 2009; Perkmann et al. 2013) and in interaction grounded in education activities (Perkmann and Walsh 2007; Thune 2009). Specifically, we document a wave of initiatives meant to institutionalise contacts between the university and external organisations.

We refer to such university-level initiatives as structured relations, on the further contingency that their implementation involves active efforts by central administrators and dedicated support staff, as well as a central element of faculty involvement. In terms of commitment and duration, the structured relations identified in a review at nine Swedish universities were found to range from the organisation of one-day events involving several outside organisations to multi-year partnership agreements with a single external organisation.

While our review suggested that most, if not all, structured relation initiatives that were identified were introduced in the last few years, we are not proposing that the involvement of centrally placed decision-makers in external relationships is an entirely recent phenomenon.

\footnotetext{
$\overline{{ }^{2} \text { We have not been able to compile }}$ precise estimates on the costs of the structured relation initiatives identified in the review. It may be noted, however, that the level of resource commitment to a particular structure can be expected to increase in all three dimensions with both duration and scope - at least as far as the costs of managing the structure itself are concerned. In this sense, setting up multi-year partnership agreements would seem to represent the most significant type of strategic commitment that was identified in the review.
} 
Elements of what we here have named 'structured relationships' have existed among universities for a fairly long time (c.f. Lee 2011), certainly also among the Swedish universities that we have studied in this paper. Clark (1998) described the evolvement of an 'enhanced developmental periphery' among his five cases of 'entrepreneurial universities', which partly related to the emergence of administrative offices tasked with supporting outreach activities. Jones-Evans et al. (1999) observe proactive, relationship-building activities on behalf of industry liaison officers at four Swedish universities in the latter half of the 1990s. Indeed, many TTOs and liaison offices have for a long time talked and thought about their tasks in similar terms (establishing relationships, etc). In practice, however, the networks developed by these offices have typically been strongly oriented towards its main functions of research commercialisation in general and IPR management in particular (Fisher and Atkinson-Grosjean 2002; Geuna and Muscio 2009). The expectation on these offices has typically been formulated in terms of patent activity and spin-off creation, rather than in terms of the development of a university's portfolio of joint research projects and education-oriented exchange with industry.

Grounding our analysis in collective action theory, we show that institutionalisation of external contacts has non-trivial implications for the functioning of universities as organisations and for university-industry interaction. By moving away from a fully decentralised (non-)organisation of outreach activities, the introduction of structured relations may contribute to change both external and internal perceptions of what a university is, and to a transformation of the way universities operate as organisations (Pinheiro and Stensaker 2014b; Pinheiro et al. 2015). We may think about a movement from ad hoc, individualbased relationships between higher education institutions and external organisations as an instance of change from organised anarchy (Cohen et al. 1972) towards the university as a strategic actor (Krücken and Meier 2006). The structured relation initiatives that were identified in our review serve the joint purpose of introducing elements of relationship management of a type associated with more 'traditional' forms of organisations (Palmatier et al. 2006; Payne and Frow 2005). Specifically, it contributes to changing the expectations of mandates and functions in the university organisation.

This paper contributes to our understanding of trends and developments in universities' external engagement activities, and their potential consequences. It primarily does so by offering a set of conceptual contributions, which are relevant both to the ongoing discussion on the governance of universities alluded to in the previous paragraph and to the discussion of the 'entrepreneurial university' and its role in society.

The first such contribution of the paper is to provide a theoretically informed framework for discussing the phenomenon of structured relations at universities as a phenomenon in and of itself. In particular, we argue that it is useful to delineate the set of activities that we have referred to as structured relations from the more traditional instruments of research commercialisation. These include traditional technology transfer offices tasked with IPR management and support of new form formation (Debackere and Veugelers 2005; Siegel and Wright 2015). Structured relation initiatives, on the other hand, are focused on relationship management, joint research and teaching-oriented interaction of structured relations. As such, we argue, structured relation initiatives have potentially more far-reaching consequences for universities and their future income streams as well as organisational identities than the traditional tech-transfer tools. In their capacity as university-level initiatives, the structured relation initiatives are also set apart from the long-existing plethora of university research centres and other collaboration structures managed and controlled from an organisational level well below that of the rector and the central university administration. We furthermore 
demonstrate that structured relation is a theoretically separate phenomenon from commercialisation support, in terms of what fundamental tensions that are triggered. Whereas commercialisation of research through immaterial property rights protection challenges academic tradition by introducing private good characteristics into the products of public science (Slaughter and Rhoades 2004), structured relations generate tensions by introducing public good characteristics into external relationship activities.

A second contribution of the paper is to offer a systematic analysis of in what ways institutionalised relationship may be an advantage to the university as an organisation. Specifically, we show that structured relation initiatives may help overcome limitations of fully professorcentred external relationships in how many actors a university reaches out to, and in the duration and thematic scope of relationships. We also empirically identify three categories of structured relations (meeting events, collaboration platforms, partnership agreements) each positioned to overcome a different set of these limitations. In this way, the paper offers concrete insights into a development towards a more proactive behaviour of universities in regard to their external relationships that has been outlined or suggested in previous research (Alarcón-del-Amo et al. 2016; Jongbloed et al. 2008; Lee 2011; Pinheiro and Stensaker 2014a).

Several aspects of structured relation initiatives would seem to deserve further research. From the point of view of university management and university policy, several questions about the effects of structured relation initiatives need to be addressed. How may structured relation initiatives be implemented so as to avoid 'crowding out' other forms of collaboration and interactions, and to reduce tensions? What portfolios of structures and initiatives may be used to build valuable relations to external organisations, and how may the performance of such structures be assessed? The case of structured relations in universities would also seem to provide an interesting starting point from which to explore the more general issue of interorganisational exchange in knowledge-intensive organisational contexts, and the opportunities and constraints of orchestrated action in such settings.

In analysing the phenomenon of structured relations, we have grounded our analysis of both the rationale for this development and of its consequences in collective action theory. Our analysis has demonstrated how this perspective, which to date has not been much utilised in higher education studies, provides a useful structure for interpreting the introduction of new organisational capabilities in the domain of universities' external relations. We believe that further research could draw on this perspective to tackle central questions about opportunities and limitations of organisational reform in universities, and about fruitful strategies to manage the tensions that often arise in the context of such reform.

Open Access This article is distributed under the terms of the Creative Commons Attribution 4.0 International License (http://creativecommons.org/licenses/by/4.0/), which permits unrestricted use, distribution, and reproduction in any medium, provided you give appropriate credit to the original author(s) and the source, provide a link to the Creative Commons license, and indicate if changes were made.

Publisher's note Springer Nature remains neutral with regard to jurisdictional claims in published maps and institutional affiliations.

\section{References}

Alarcón-del-Amo, M., Casablancas-Segura, C., \& Llonch, J. (2016). Responsive and proactive stakeholder orientation in public universities: antecedents and consequences. Higher Education, 72(2), 131-151. 
Altbach, P. G. (2001). Academic freedom: International realities and challenges. Higher Education, 41(1-2), 205-219.

Becher, T., \& Trowler, P. (2001). Academic tribes and territories: intellectual enquiry and the culture of disciplines. New York: McGraw-Hill Education.

Benneworth, P., \& Jongbloed, B. W. (2010). Who matters to universities? A stakeholder perspective on humanities, arts and social sciences valorisation. Higher Education, 59(5), 567-588.

Benneworth, P., Pinheiro, R., \& Sánchez-Barrioluengo, M. (2016). One size does not fit all! New perspectives on the university in the social knowledge economy. Science and Public Policy, 43(6), 731-735.

Blaschke, S., Frost, J., \& Hattke, F. (2014). Towards a micro foundation of leadership, governance, and management in universities. Higher Education, 68(5), 711-732.

Boardman, P. C., \& Ponomariov, B. L. (2009). University researchers working with private companies. Technovation, 29(2), 142-153.

Brunsson, N., \& Sahlin-Andersson, K. (2000). Constructing organizations: the example of public sector reform. Organization Studies, 21(4), 721-746.

Bstieler, L., Hemmert, M., \& Barczak, G. (2015). Trust formation in university-industry collaborations in the US biotechnology industry: IP policies, shared governance, and champions. Journal of Product Innovation Management, 32(1), 111-121.

Clark, B. R. (1983). The higher education system: academic organization in cross-national perspective. Los Angeles: University of California Press.

Clark, B. R. (1998). Creating entrepreneurial universities: organizational pathways of transformation. Oxford: Pergamon-Elsevier Science.

Cohen, M. D., March, J. G., \& Olsen, J. P. (1972). A garbage can model of organizational choice. Administrative Science Quarterly, 1-25.

Debackere, K., \& Veugelers, R. (2005). The role of academic technology transfer organizations in improving industry science links. Research Policy, 34(3), 321-342.

DiMaggio, P., \& Powell, W. W. (1983). The iron cage revisited: collective rationality and institutional isomorphism in organizational fields. American Sociological Review, 48(2), 147-160.

Fisher, D., \& Atkinson-Grosjean, J. (2002). Brokers on the boundary: academy-industry liaison in Canadian universities. Higher Education, 44(3), 449-467.

Fumasoli, T., \& Lepori, B. (2011). Patterns of strategies in Swiss higher education institutions. Higher Education, $61,157-178$.

Geuna, A., \& Muscio, A. (2009). The governance of university knowledge transfer: a critical review of the literature. Minerva, 47, 93-114.

Geuna, A., \& Piolatto, M. (2016). Research assessment in the UK and Italy: costly and difficult, but probably worth it (at least for a while). Research Policy, 45(1), 260-271.

Gornitzka, Å. (1999). Governmental policies and organisational change in higher education. Higher Education, $38(1), 5-31$.

Guerrero, M., \& Urbano, D. (2012). The development of an entrepreneurial university. The Journal of Technology Transfer, 37(1), 43-74.

Heitor, M. (2015). How university global partnerships may facilitate a new era of international affairs and foster political and economic relations. Technological Forecasting and Social Change, 95, 276-293.

Jones-Evans, D., Klofsten, M., Andersson, E., \& Pandya, D. (1999). Creating a bridge between university and industry in small European countries: the role of the Industrial Liaison Office. R\&D Management, 29(1), 4756.

Jongbloed, B., Enders, J., \& Salerno, C. (2008). Higher education and its communities: interconnections, interdependencies and a research agenda. Higher Education, 56(3), 303-324.

Jonsson, L., Baraldi, E., \& Larsson, L. E. (2015). A broadened innovation support for mutual benefits: academic engagement by universities as part of technology transfer. International Journal of Technology Management \& Sustainable Development, 14(2), 71-91.

Kaulio, M. A. (1998). Customer, consumer and user involvement in product development: a framework and a review of selected methods. Total Quality Management, 9(1), 141-149.

Kenney, M., \& Patton, D. (2009). Reconsidering the Bayh-Dole Act and the current university invention ownership model. Research Policy, 38(9), 1407-1422.

Klofsten, M., \& Jones-Evans, D. (2000). Comparing academic entrepreneurship in Europe-the case of Sweden and Ireland. Small Business Economics, 14(4), 299-309.

Koput, K. W. (1997). A chaotic model of innovative search: some answers, many questions. Organization Science, 8(5), 528-542.

Krücken, G., \& Meier, F. (2006). Turning the university into an organizational actor. In G. S. Drori, J. W. Meyer, \& H. Hwang (Eds.), Globalization and organization: world society and organizational change (pp. 241257). Oxford: Oxford University Press. 
Krücken, G., Blümel, A., \& Kloke, K. (2013). The managerial turn in higher education? On the interplay of organizational and occupational change in German academia. Minerva, 51(4), 417-422.

Laursen, K., \& Salter, A. (2006). Open for innovation: the role of openness in explaining innovation performance among UK manufacturing firms. Strategic Management Journal, 27(2), 131-150.

Lee, K. J. (2011). From interpersonal networks to inter-organizational alliances for university-industry collaborations in Japan: the case of the Tokyo Institute of Technology. R\&D Management, 41(2), 190-201.

Lefton, M., \& Rosengren, W. (1966). Organizations and clients: lateral and longitudinal dimensions. American Sociological Review, 31(6), 802-810.

Maassen, P., \& Potman, H. (1990). Strategic decision making in higher education: an analysis of the new planning system in Dutch higher education. Higher Education, 20, 393-410.

Maassen, P., \& Stensaker, B. (2011). The knowledge triangle, European higher education policy logics and policy implications. Higher Education, 61(6), 757-769.

Mowery, D. C., Nelson, R. R., Sampat, B. N., \& Ziedonis, A. A. (2015). Ivory tower and industrial innovation: university-industry technology transfer before and after the Bayh-Dole Act. Palo Alto: Stanford University Press.

Musselin, C. (2013). Redefinition of the relationships between academics and their university. Higher Education, $65(1), 25-37$.

Olsen, J. O. (2007). The institutional dynamics of the European university. In J. P. Olsen \& P. Maassen (Eds.), University dynamics and European integration (pp. 25-54). Dordrecht: Springer.

Olson, M. (1971). The logic of collective action: public goods and the theory of groups. In Harvard Economic Studies 124 (2nd ed.). Cambridge: Harvard University Press.

Ostrom, E. (1998). A behavioral approach to the rational choice theory of collective action: Presidential address, American Political Science Association, 1997. American Political Science Review, 92(1), 1-22.

Palmatier, R. W., Dant, R. R., Grewal, D., \& Evans, K. R. (2006). Factors influencing the effectiveness of relationship marketing: a meta-analysis. Journal of Marketing, 70(4), 136-153.

Payne, A., \& Frow, P. (2005). A strategic framework for customer relationship management. Journal of Marketing, 69(4), 167-176.

Perkmann, M., \& Walsh, K. (2007). University-industry relationships and open innovation: towards a research agenda. International Journal of Management Reviews, 9(4), 259-280.

Perkmann, M., Tartari, V., McKelvey, M., Autio, E., Broström, A., D’Este et al. (2013). Academic engagement and commercialisation: A review of the literature on university-industry relations. Research Policy, 42(2), $423-442$.

Pinheiro, R., \& Stensaker, B. (2014a). Strategic actor-hood and internal transformation. In J. Branković, M. Klemenčić, P. Lažetić, \& P. Zgaga (Eds.), Global challenges, local responses in higher education. Higher Education Research in the 21st Century Series. Rotterdam: SensePublishers.

Pinheiro, R., \& Stensaker, B. (2014b). Designing the entrepreneurial university: the interpretation of a global idea. Public Organization Review, 14, 497-516.

Pinheiro, R., Geschwind, L., \& Aarrevaara, T. (2014). Nested tensions and interwoven dilemmas in higher education: the view from the Nordic countries. Cambridge Journal of Regions, Economy and Society, 7(2), 233-250.

Pinheiro, R., Langa, P. V., \& Pausits, A. (2015). The institutionalization of universities' third mission: introduction to the special issue. European Journal of Higher Education, 5(3), 227-232.

Ponomariov, B. L., \& Boardman, P. C. (2010). Influencing scientists' collaboration and productivity patterns through new institutions: university research centers and scientific and technical human capital. Research Policy, 39(5), 613-624.

Ramirez, F. O., \& Christensen, T. (2012). The formalization of the university: rules, roots, and routes. Higher Education, 65(6), 695-708.

Redford, D. T., \& Fayolle, A. (2014). Stakeholder management and the entrepreneurial university. In A. Fayolle \& D. T. Redford (Eds.), Handbook on the entrepreneurial university (pp. 11-24).

Siegel, D. S., \& Wright, M. (2015). University technology transfer offices, licensing, and start-ups. In A. N. Link, D. S. Siegel, \& M. Wright (Eds.), Chicago handbook of university technology transfer and academic entrepreneurship (pp. 1-40).

Slaughter, S., \& Rhoades, G. (2004). Academic capitalism and the new economy: markets, state, and higher education. Baltimore: John Hopkins University Press.

Tapper, T., Palfreyman, D. (2011). Oxford, the Collegiate University: Conflict, Consensus and Continuity. Springer.

Thune, T. (2009). Doctoral students on the university-industry interface: a review of the literature. Higher Education, 58(5), 637-651. 
Torbert, W. R., \& Taylor, S. S. (2008). Action inquiry: Interweaving multiple qualities of attention for timely action. In P. Reason, H. Bradbury (Eds.), The SAGE handbook of action research: Participative inquiry and practice (pp. 239-251). London: SAGE.

Trow, M. (1994). Managerialism and the academic profession: the case of England. Higher Education Policy, 7 , $11-18$.

Weick, K. E. (1976). Educational organizations as loosely coupled systems. Administrative Science Quarterly, 21, 1-19.

Yin, R. K. (1989) Case study research: Design and methods. Newbury Park, CA: Sage. 